\title{
eLyra
}

\section{Vocoperformance à brasileira}

\section{Leonardo Davino de Oliveira \\ Universidade do Estado do Rio de Janeiro}

Resumo: Além de singularizar o modus cancional brasileiro, o texto tem o objetivo de sugerir reflexões em torno da ideia de Brasil como espaço utópico do vértice da experiência humana do cotidiano. Para tanto, proponho pensar a canção popular enquanto suporte de gaia ciência e jogo lúdico, portanto, lugar da criação, permitindo ao brasileiro a reconstrução contínua de sua mitopoética: identidades e entidades, vontade de potência e terapêutica do recalque.

Palavras-chave: Vocoperformance, canção popular brasileira, identidades

Abstract: In addition to singling out the Brazilian music, the text has the objective of suggesting reflections around the idea of Brazil as utopian space of the vertex of the human experience of daily life. For that, I propose to think about the popular song as a support of science gaya and ludic play, therefore, place of creation, allowing the Brazilian to the continuous reconstruction of their mythopoetics: identities and entities, willpower and therapeutics of repression.

Keywords: Vocoperformance, Brazilian popular music identities 
A expressão "indústria cultural” foi cunhada por Theodor Adorno e Max Horkheimer no livro Dialética do Esclarecimento e se tornou uma referência para o pensamento sobre o culto à técnica e à racionalidade. Ora bem, ora mal utilizado, em resposta que vai ao encontro daquilo que os autores viam como a barbárie do esclarecimento (do lluminismo), o fato é que o conceito ainda merece atenção no que se refere à sua vigência. No capítulo "A Indústria Cultural. O Esclarecimento como mistificação das massas", os autores anotam:

A racionalidade técnica hoje é a racionalidade do próprio domínio, é o caráter repressivo da sociedade que se autoaliena. [...] A passagem do telefone ao rádio dividiu de maneira justa as partes. Aquele, liberal, deixava ainda ao usuário a parte de sujeito. Este, democrático, torna todos os ouvintes iguais ao sujeitá-los, autoritariamente, aos idênticos programas das várias estações. (Adorno/Horkheimer 1985: 114-115)

Fica evidente a crítica dos autores à massificação imposta pela indústria cultural, "engolidora de talentos", já que estes "pertencem à indústria muito antes que esta os apresente" (ibidem). Vértice da convergência entre o pensamento de Marx e a filosofia de Hegel, a crítica de Adorno e Horkheimer polariza, de um lado, os empresários que impõem rigidez quanto às opções culturais; e, de outro lado, o consumidor, refém alienado de/por tal autoritarismo. Vivendo os horrores da Segunda Guerra e impressionados com o desenvolvimento das indústrias de cinema e de fonograma, os autores exilados parecem descartar a possibilidade de rebelião dos consumidores, ou seja, negam a capacidade de escolha - os modos de uso - dos ouvintes submetidos à tirania da indústria, como se estes, desde sempre, individual e coletivamente, não soubessem impor vontade diante das ofertas.

É preciso salientar que não negamos a relevância das formulações de Adorno e Horkheimer. Por exemplos, suas observações sobre os aspectos econômicos no âmbito da arte e a transição entre a audição "ao vivo" de um artista e a audição deste artista pelos meios mecânicos do fonógrafo, numa clara conjunção de percepção de perda daquilo que Walter Benjamin chamou de "aura" - o ritual sagrado - da arte, quando tratou da reprodutibilidade técnica. Como podemos perceber nos anúncios dos equipamentos de reprodução da época, havia um forte empenho da indústria para fazer crer que não havia diferença entre a voz gravada e a estrela da ópera, que agora poderia ser "levada para casa" e ouvida quando o consumidor bem desejasse. Isso atemorizava os pensadores, pois 
representava a negação da subjetividade tanto do artista - multiplicado -, quanto do ouvinte - autoiludido. Eles temiam o cerceamento da criatividade das massas e a centralização do poder de escolha, diante do rigor da indústria. Adorno e Horkheimer viam no lucro dos empresários a mesma rigidez do nazifascismo.

Se Adorno não admitia que os consumidores fossem "reduzidos a material estatístico", revoltava-se com energia ainda maior contra a possibilidade de a produção cultural de uma determinada sociedade vir a ter sua comercialização organizada da mesma maneira que a distribuição dos produtos habituais. A comercialização feita segundo as posses das camadas sociais determinava uma planificação da produção, o que parecia a Adorno inaceitável. (Puterman 1994: 14)

Ao pensarem motivados pela degradação da Guerra, que para eles era o ápice da irracionalidade, Adorno e Horkheimer parecem esquecer que as diferenças culturais de educação e formação sempre existiram e continuariam a existir, pois o signo da subjetividade está no modo afetivo de usar as tecnologias. Mesmo que a indústria quisesse vender um "mesmo" produto a todos, o indivíduo é capaz de transvalorar. Pensar o contrário seria acreditar na genialidade das camadas mais abastadas, dos donos da indústria, em oposição a uma massa uniforme de povo, cuja "arte legítima" estaria sempre em processo de degradação. Eles "não levaram em consideração o devenir constante das diferenciações internas das sociedades, em relação às quais o progresso tecnológico age também como um fator de variações", escreve Puterman (idem: 22). Os pensadores viram na indústria cultural um meio de "classificar e organizar os consumidores a fim de padronizálos" (Adorno/Horkheimer 1985: 116).

Hoje em dia, com o levante de várias e diferenciadas vozes socioculturais no campo da canção, facilitado pelos suportes tecnológicos, fica difícil identificar a falência dos "marginais" (sociais e econômicos) à indústria, sobre os quais Adorno e Horkheimer focaram suas preocupações. Mesmo "artes genuínas", "populares" e "folclóricas" parecem ter, ao pactuarem com a indústria, subvertido o mercado a fim de permanecer e circular na cultura, subvertendo, outrossim, a premissa que diria que "a indústria cultural não sublima, mas reprime e sufoca" (idem: 140).

Não deixamos de concordar com os autores quando escrevem que o esclarecimento também serve ao totalitarismo e que "a indústria cultural fornece como paraíso a mesma 
vida cotidiana. Escape e elopement são determinados, a priori, como meios de recondução ao ponto de partida. O divertimento promove a resignação que nele procura se esquecer" (idem: 142). No entanto, também somos levados a crer na capacidade de, ao invés da anestésica "resignação", ressignificação do produto por parte do consumidor.

Por esta perspectiva, o autor (a autoria) passa a interessar. Um disco não é comprado pelo simples fato de ser um disco, mas por nele conter a voz de alguém. É este alguém-autor que interessa ao consumidor de canção, e não, por exemplo, a marca do disco, ou se ele é desta ou daquela gravadora. Isso indicia respostas para o alardeado "fim do disco" e, consequente, queda das grandes gravadoras. O que, por sua vez, não implica no "fim da canção", nem, muito menos, no fim do artista cancionista, posto que este será seguido pelo ouvinte-consumidor aonde for. Talvez porque estivessem legitimamente horrorizados pela guerra, Adorno e Horkheimer não tenham conseguido vislumbrar o poder de adaptação - o contrário de acomodação - do indivíduo e da arte. O projeto de um "ser genérico", com sua falência dos valores humanistas, pretendido pela indústria cultural, parece ter falhado.

Fica claro que as "forças de manipulações e controle" não deixam de tentar impor suas normas. É isso que os versos da canção "Quem vai ficar no gol?", de Erasmo Carlos e Roberto Carlos (Pra Falar de Amor 2001), tematiza:

\footnotetext{
Paulo gravou um disco que não tocou em nenhum lugar

Se o povo não escuta, não cai no gosto e não vai comprar

É que o rádio só toca o que o povo quer escutar

E o povo só compra o que ouviu o rádio tocar.
}

Essa dicotomia "só toca o que vende" versus "só vende o que toca" parece ter como base a dialética de Adorno e Horkheimer e suas críticas à propaganda interessada. Como sabemos, a "democrática" (termo também questionado por Adorno e Horkheimer) internet tornou-se um meio de romper com os esquemas de manipulação. Será? Hoje, o vídeo de um anônimo pode alcançar a fama com a mesma competência com que um produto "feito para dar certo e vender" pode encalhar. Claro que tudo é atravessado pela velocidade que une e separa fama e esquecimento, bem como pela questão do gosto pelo inusitado. Mas estes são outros problemas. Assim como dizer se este ou aquele produto é bom ou ruim depende 
da resposta dada às perguntas: bom/ruim para o quê? Pra quem? Virá da resposta sem preconceitos a estas perguntas a eliminação da terrível expressão "lixo cultural".

O certo é que o público de hoje parece não esperar mais que alguém dite o que deve e o que não deve ser consumido - termo complexo para o Umberto Eco de Apocalípticos e Integrados (2001). A interatividade revoluciona o contato do público com a obra. O ouvinte hoje pode comprar apenas a canção que Ihe toca, sem precisar "gastar dinheiro" com um disco. O que precisamos destacar é a intervenção do humano nesse processo. "Quem vai ficar no gol?", pergunta o sujeito da canção cantada por Erasmo Carlos. Afinal:

\footnotetext{
Quando o salário aumenta, a voz do povo quer festejar

É mais uma graninha no fim do mês pra poder gastar

Só que pra ter o aumento o dinheiro sai de algum lugar

E seja de onde for, é o próprio povo quem vai pagar. (Carlos 2001)
}

Ou seja, a canção usa a indústria para criticar a própria indústria. Isso é rebelião pelo jogo, pela arte. Se um indivíduo não passa pelo mesmo rio duas vezes, posto que tanto o rio quanto o indivíduo estão sempre em (trans)formação, uma canção e um ouvinte não se cruzam duas vezes: de dentro dos mecanismos de repetição, cada escuta é singular e depende de inúmeros fatores impostos ao instante-já do momento cancional.

É óbvio que a técnica, por si, como alguns acreditavam, não satisfaz as necessidades do humano. Nisso Adorno e Horkheimer estão certos. Necessidades que são criadas e alimentadas pela indústria e absorvidas neuroticamente por tantos. Porém, como tão lucidamente o próprio Adorno observou no texto "Lírica e Sociedade":

A lírica se mostra mais profundamente garantida socialmente ali onde não fala segundo o paladar da sociedade, onde nada comunica, onde, ao contrário, o sujeito, que acerta com a expressão feliz, chega ao pé de igualdade com a própria linguagem, ao ponto onde esta, por si mesma, gostaria de ir. (1980: 198)

Quando isso ocorre na canção popular, e ocorre com mais frequência do que a teoria pode controlar, podemos dizer que o instinto caraíba se manifesta, que a gaia ciência se enriquece e que o mais que humano em nós se realiza. Estou falando, como Adorno, que 
o instante do esquecimento de si em que o sujeito submerge na linguagem não é o sacrifício dele ao ser. Não é um instante de violência, nem sequer de violência contra o sujeito, mas um instante de conciliação: só é a própria linguagem quem fala quando ela não fala mais como algo alheio ao sujeito, mas como sua própria voz. (idem: 199)

É no complexo jogo entre o conhecer (razão) e o reconhecer (estranhamento) que vivemos e cantamos a vida, a partir do contato com os sujeitos cancionais neossirênicos midiatizados.

Dito isso, é preciso fazer a distinção entre cancionista e neossereia. Enquanto o primeiro "tem um controle de atividade que permite equilibrar a melodia no texto e o texto na melodia, distraidamente, como se para isso não despendesse qualquer esforço" (Tatit 1996: 9),

é um gesticulador sinuoso com uma perícia intuitiva muitas vezes metaforizada com a figura do malandro, do apaixonado, do gozador, do oportunista, do lírico, mas sempre um gesticulador que manobra sua oralidade, e cativa, melodicamente, a confiança do ouvinte, (ibidem)

a neossereia se utiliza das configurações do cancionista para situar o ouvinte no mundo. Dito de outro modo, e de forma perigosamente reducionista, mas absolutamente verificável, podemos dizer que toda neossereia é cancionista em ação, mas nem todo cancionista é neossereia, posto que para ser esta aquele depende do sujeito cancional gerado da aproximação entre quem canta e quem ouve. Ou seja, a neossereia está quando o sujeito cancional - a entidade concreta e invisível resultado da fruição e do entendimento do ouvinte - se materializa. O cancionista se torna neossereia por apontar/cantar a gaia ciência.

E isso não tem nada de metafísico, ou muito pouco. "É sobre nossos sentidos, e unicamente sobre eles, que a música age diretamente (mesmo no canto vocal, existe 'um charme anterior ao da expressão')" (Lévi-Strauss 1997: 73), anota Claude Lévi-Strauss em Olhar Escutar Ler. A neossereia é a voz que canta o ouvinte de dentro e por trás da entoação do cancionista. Esta voz carrega a mitologia do ouvinte que se reconhece plasmado no modo charmoso e caprichoso de dizer do cancionista. São as relações estabelecidas e equalizadas pelo cancionista entre o ouvinte e o mundo ao redor que proporcionam a permanência do canto sirênico: tão individual quanto efêmero, pois depende do instante-já da escuta. É 
assim que a semântica contida na letra de uma canção, pensada pelo compositor, pode expandir seus significados.

O canto sirênico equilibra, não necessariamente sem dor para quem ouve, os acontecimentos que o precederam e aqueles que o seguem. O contato com o canto sirênico entoado pelo cancionista promovido a neossereia faz o ouvinte se reencontrar com o ritmo da própria existência. E isso ignora o "bom" e o "mau" gosto, os conceitos em torno do "lixo cultural", bem como ignora o pensamento que diz que um ouvido treinado, refinado e sensível prescinde das palavras. Ora, se são as palavras vocalizadas por alguém o que afirma a existência deste alguém - irmão/cúmplice do ouvinte no mundo, porque se reconhece naqueles sentimentos performatizados na voz -, como desprezá-las e fazer desse desprezo um sintoma de sensibilidade superior? As palavras não enfraquecem a universalidade da linguagem musical, posto que é no ritmo, tal e qual pensado por Octávio Paz, dado a elas pela voz de alguém - que aqui chamo neossereia -, mais do que naquilo que elas dizem, que reside a eficácia do despertar das sensações. "A melodia entoativa é o tesouro óbvio e secreto do cancionista", escreve Tatit (1996: 11). No laço tecido entre as palavras e seus sons - equilibrados na voz sirênica - mora o êxito da comunicação, a eficácia da canção: resultado do pacto entre locutor (destinador) e ouvinte (destinatário). Esse pacto rege a premissa de que aquela maneira de dizer do destinador é a que melhor diz o desejo do ouvinte. Este sabe que aquele "é um fingidor / Finge tão completamente / Que chega a fingir que é dor / A dor que deveras sente" (Pessoa 1971: 104).

“Eu minto, mas minha voz não mente", canta Maria Bethânia (Drama 1972).

\author{
Mesmo que os cantores sejam falsos como eu \\ Serão bonitas, não importa
}

São bonitas as canções, (Buarque 2012)

canta Chico Buarque (Na Carreira 2012). É a neossereia quem mente sentir o que de fato sente, pelo ouvinte, para enredar este na sedução. O ouvinte, sempre carente de mentiras sinceras que the estimulem verdades, encontra na credibilidade entoativa do cancionista o canto sirênico necessário. Tomando como exemplo a canção "Choro Bandido", de Edu Lobo e Chico Buarque, cujos versos iniciais já foram aqui citados - "Mesmo que os 
cantores sejam falsos como eu / Serão bonitas, não importa / São bonitas as canções" -, podemos identificar o mecanismo da passionalização como elemento persuasivo utilizado pelo cancionista de choro bandido, desonesto, fingido.

Composta para a peça O Corsário do Rei (1985), de Augusto Boal, "Choro Bandido", ao ir revelando as estratégias de autorreflexão do sujeito da canção - portanto, sendo metacanção -, aponta alguns dos mecanismos de sedução utilizados pela neossereia: o fingimento - "Mesmo que você feche os ouvidos / E as janelas do vestido / Minha musa vai cair em tentação" (Buarque 2012) - e a mirada retrospectiva da história do gesto de cantar "Quando um deus sonso e ladrão / Fez das tripas a primeira lira / Que animou todos os sons / E daí nasceram as baladas / E os arroubos de bandidos como eu" (idem).

A referência ao deus grego Hermes é clara. Protetor dos ladrões, ele teria construído a primeira lira, instrumento de acompanhamento rítmico-melódico da poesia. Em um de seus hinos, Homero assim descreve o ato:

\footnotetext{
Ajustou, na medida, umas talas de cálamo exatas,

$E$, do dorso através e da pele, enfiou no quelônio

E, conforme pensava, uma pele de boi esticou

E dois braços extremos dispôs, por travessa ajuntados.

Sete cordas de tripa de ovelha estendeu harmoniosas.

Ao depois de fazê-lo, tomou do amorável brinquedo

E co'um plectro uma a uma provou cada corda, aos seus dedos

Ressoava tremenda. (Homero 2003: v. 44-53)
}

Aí estão as tripas de que fala o sujeito da canção "Choro Bandido". Mas ele vai além, pois, se tomarmos a expressão de domínio público "fez das tripas coração", entendemos que o que o sujeito da canção, malandro, está tematizando é o fingimento implícito a toda canção. Ele faz da dor do desejo (das tripas) de não ter o outro o motor (coração) do canto. O engenho é complexo e bonito, feito para seduzir o ouvinte.

Assim, a referência ao deus Hermes quer significar o próprio trabalho do artista cancionista, poeta - criador do sujeito da canção (eu lírico). Ele sabe que "a beleza existe sozinha", como canta Arnaldo Antunes em "Itapuana" (Saiba 2004), e aponta para sua intervenção de cantor como aquilo que, falseando sentimentos e sensações, embeleza e 
assalta a vida do outro (ouvinte) no tecido das palavras e da melodia na voz. É assim que o sujeito promove a sua canção a canto de sereia. O sujeito de "Choro Bandido" é lúcido e tematiza as peripécias de todo cancionista: a malandragem necessária para equilibrar oralidade e vocalidade, palavra na melodia, com o objetivo da sedução, do roubo dos sentidos do ouvinte. Situação da qual nem Ulisses escapou: "Mesmo que você feche os ouvidos / E as janelas do vestido, / Minha musa vai cair em tentação". Em Homero, na verdade, são os companheiros de Ulisses quem têm os ouvidos tapados, porém, segundo o sujeito da canção, contrariando Adorno, nem mesmo estes se mantiveram imunes ao canto das sereias, já que podiam imaginar:

Uma rodela de cera cortei com meu bronze afiado, em pedacinhos, e pus-me a amassá-los nos dedos possantes.

Amoleceu logo a cera, por causa da força empregada

e do calor grande de Hélio, o senhor Hiperiônio esplendente.

Sem exceção, depois disso, tapei os ouvidos dos sócios

$[\ldots]$

[...] fiz sinal com os olhos aos sócios que as cordas

me relaxassem; mas eles remaram bem mais ardorosos. (Homero 2000: 214)

O canto mavioso, que desvia o ouvinte da rota segura em direção à morte, está concentrado nos versos:

\footnotetext{
E eis que menos sábios do que antes

Os seus lábios ofegantes

Hão de se entregar assim:

Me leve até o fim.

Me leve até o fim. (Buarque 2012)
}

Ou seja, embriagado no enredo vocal, no jogo poético, caberá ao ouvinte pedir mais, para ir mais fundo e até o fim. Versos como "Mesmo porque estou falando grego / Com sua imaginação" (idem) reforçam a tese de Tatit de que em canção não importa muito o que é dito, mas o modo - a gestualidade - do dizer. 
Tomando ainda como referência a mitologia grega para decifrar seus modos de bandido, de jogador que dribla os empecilhos, o sujeito dirá: "Mesmo que você fuja de mim / Por labirintos e alçapões, / Saiba que os poetas, como os cegos, / Podem ver na escuridão" (idem), referindo-se ao labirinto de Dédalo e ao adivinho Tirésias. É quando, semelhante ao adivinho, alcança verdades incompreensíveis (das musas) ao homem comum, e traduz estas verdades para qualquer um, que o sujeito da canção, invenção do cancionista, promove este a neossereia. E vale ressaltar que para o sujeito de "Choro Bandido" a musa é o próprio outro-ouvinte da canção. É deste que o sujeito astuto retira os elementos de sedução carências e excessos -, devolvendo tudo de forma processada esteticamente, fingida, sedutora. Só o fato de instituir o outro ao status de musa já se configura como armadilha lançada.

Noutras palavras, Chico Buarque é cancionista - o autor, o compositor e o entoador/destinador - de "Choro Bandido". E é neossereia quando sua voz, ao entrar no ouvido do ouvinte, promove o surgimento do sujeito cancional e, consequentemente, como resultado do embate entre esse sujeito e o ouvinte, o reposicionamento deste no mundo. Mas voltemos ao tema principal deste ensaio.

"Ou o mundo se brasilifica ou vira nazista". "Jesus de Nazaré e os tambores do Candomblé". As duas emblemáticas frases de Jorge Mautner sintetizam o pensamento, a vida e a obra deste inquieto artista pensador. No texto "A Amálgama do Brasil Universal", Mautner anota que

\footnotetext{
os escravos trazidos da África ao chegarem aqui reinterpretam suas crenças religiosas e criam o nosso candomblé que, em primeiro lugar, transforma os Orixás que, em sua origem, são de determinados lugares geograficamente determinados. [...] Os orixás se transformam em arquétipos de várias conexões e novos significados em velocidade quântica. Além do jogo de búzios, onde entra o acaso e a emoção de quem os joga e interpreta, e cujo critério e conteúdo são iguais e paralelos ao princípio e estrutura do cálculo da incerteza matematicamente elaborado por Heisenberg. (2012: 110-111)
}

Defensor e divulgador do "amálgama Brasil", do país como "vértice da humanidade", Mautner valoriza os processos de mestiçagem, miscigenação, hibridização que compõem o povo brasileiro: esta "massa" misteriosa e complexa. 
Essa formidável absorção do outro em plenitude de dignidade resplandecente é a característica do povo brasileiro! Chineses, japoneses, judeus, sírio-libaneses, e todos os seres humanos de todas as culturas e povos do planeta têm aqui os seus parentes e descendentes, e trazem todas as suas culturas para cá e imediatamente se sentem à vontade e com imensa vontade de se misturar e se miscigenar neste redemoinho de sensações de plenitudes que vem dos mistérios de Macunaíma, e a disposição absoluta de abraçar e amar o próximo porque o próximo é o mistério para ser eternamente desvelado, porque somos todos também tupis-guaranis e nossa mitologia vem do mistério e o nosso destino e missão são se apaixonar por tudo que é estranho, novo, diferente, estrangeiro, forasteiro, desconhecido. (idem: 111-112)

"Só me interessa o que não é meu", diria Oswald de Andrade. O pensamento de Jorge Mautner vai na contramão dos movimentos que visam definir e delimitar as identidades que supostamente constituem o Brasil. Sobre o assunto, Antonio Risério escreve:

A verdade é que nada, do que chegou ao Brasil, conseguiu manter aqui uma pureza original, prébrasileira. Por isso mesmo, não existe uma diversidade incontornável separando culturalmente pretos e brancos no Brasil. E não adianta dar murro em ponta de fato. O Brasil não conhece, em escala significativa, situações, experiências ou sistemas hermeticamente isolados. (2007: 222)

\section{Mais adiante, Risério observa que}

o que temos em nosso espaço geográfico são diferenças culturais - e não culturas diferentes. É certo que não devemos extrair, das realidades objetivas da mestiçagem e do sincretismo, uma ideologia uniformizadora, apontando para a dissolução última dessas mesmas diferenças. Mas daí a travestir diferença cultural de cultura distinta vai uma enorme distância. (idem: 227)

E, ainda:

A experiência sincrética brasileira aparece hoje, a olhos de observadores estrangeiros que procuram entendê-la, como uma antecipação profunda e bem-sucedida de processos que o planeta passou a experimentar com a globalização. Como antecipação e lição. Com isso, nos tornamos reconhecidos como portadores de uma mensagem de alcance planetário. (idem: 415) 
“Mas o certo é que ninguém vai entender o Brasil se não encarar, em toda a sua abrangência e complexidade, os fenômenos fundamentais da mestiçagem e do sincretismo" (idem: 441).

Essa ideia do Brasil como "vértice da humanidade" atravessa nosso olhar sobre o país desde sempre. E é isso que, em lados aparentemente opostos, pensadores como Risério e Liv Sovik (2009) investigam. Para Sovik, é preciso "reler o diálogo entre as experiências do Brasil e dos Estados Unidos em matéria de relações raciais" (2009: 16). Para a autora, "A história americana está presente na imprensa e no senso comum brasileiros como referência negativa para o futuro das relações raciais. É importante explicar a relação da experiência brasileira com essa história de tal maneira que não se reitere simplesmente o impasse em torno da segregação versus a mestiçagem" (ibidem).

A utopia de um Brasil-vértice é uma experiência do cotidiano, como na canção "Umbigo do Mundo", de L. Cherubini, P. Faschi, M. Centoze, S. Celani e N. Motta:

\author{
Isso aqui é o umbigo do mundo \\ Onde a beleza tem muitas caras \\ cores e raças, misturas raras \\ peles de ébano, de sangue indígena \\ olhos que brilham como esmeraldas \\ caras mestiças de uma nova era \\ como o futuro que está chegando \\ sob o sol no umbigo do mundo \\ e todo mundo está sambando. (Mercury 2003)
}

Como vemos, a letra da canção trabalha sobre "a dor e a alegria" de ser e estar mestiço tropical brasileiro. Cantada por Daniela Mercury (Eletrodoméstico 2003) entre a canção "Nossa Gente" ("Nossa gente é quem bem diz é quem mais dança") e a canção "Ilê Pérola Negra" ("Eu quero penetrar no laço afro que é meu, e seu / Vem cantar meu povo, vem cantar você"), acompanhada pelo Olodum, "Umbigo do Mundo" ganha significações múltiplas, amplas. Aliás, é impressionante como uma versão, feita por Nelson Motta, para um rap italiano - "L’Ombelico del Mondo", hit do rapper Jovanotti -, interessa e traduz tanto a realidade e o pensamento brasileiros. "Só me interessa o que não é meu", repetiria aqui Oswald, em seu elogio ao nosso instinto caraíba: tupy and not tupy. 


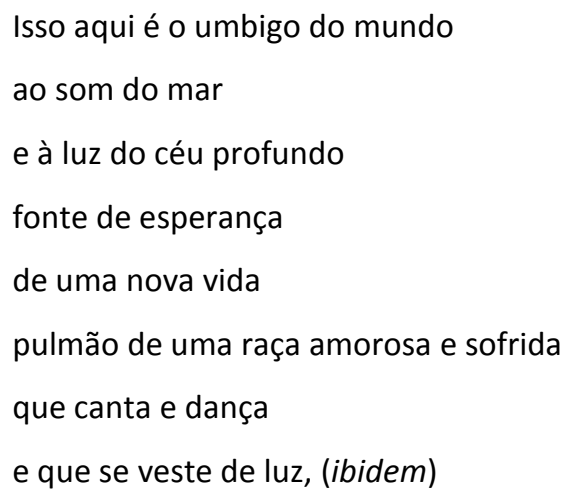

canta Daniela em cima do trio elétrico, chamando para a cena os versos do "Hino Nacional", de Joaquim Osório Duque Estrada.

Liv Sovik identifica no Brasil o afeto como

uma metáfora para a unidade nacional, para a maneira brasileira de lidar com a diferença interna. [...] Essa metáfora que associa o carinho ao brasileiro ajuda a transpor barreiras entre o ideal (e a realidade) do Brasil hospitaleiro e os fatos, visíveis em cada esquina, da desigualdade social e racial. (2009: 34-35)

Sobre Daniela Mercury, Liv Sovik se questiona: "No contexto das figurações da identidade racial consumidas pelo grande público, pensando a partir da branquitude como valor, qual é o sentido da identificação de Daniela Mercury com a cultura negra?" (idem: 162). Mais adiante, ela mesma responde: "Daniela é uma artista branca autorizada pelo seu público a identificar-se com gêneros culturais negros" (idem: 162-163); "Ela representa menos uma mediação da cultura negra por uma branca, do que a carnavalização da própria mediação" (idem: 164). Penso que Daniela em cima do trio cantando "a cor dessa cidade sou eu" é mais sintoma e menos causa, mais amálgama e menos reforço de segregação. Sintoma de uma cultura em que "brancos sempre conviveram com negros, mesmo sob a escravidão. Do que não gostam é de serem representados por eles, fora ou dentro do país" (Santos 1997: 6).

Não podemos negar as injustiças sociais que nos afetam a cada instante, e que se refletem, por exemplo, no apartheid do carnaval baiano. Pelo contrário, é encarando tais crueldades, com a valorização e o entendimento - sem separação nítida entre "as partes" -, 
que nos manteremos opostos ao assombroso apartheid norte-americano. Ou seja, aprofundar o padê - e não pregar o apartheid.

Devemos compreender "democracia racial" como significando a metáfora perfeita para designar o racismo estilo brasileiro: não tão óbvio como o racismo dos Estados Unidos e nem legalizado qual o apartheid da África do Sul, mas institucionalizado de forma eficaz nos níveis oficiais de governo, assim como difuso e profundamente penetrante no tecido social, psicológico, econômico, político e cultural da sociedade do país. (Nascimento 2016: 111)

A reivindicação feita por Abdias Nascimento, contra o "imperialismo da brancura", engendra-se na ressignificação (vigor intuitivo) dada pelo indivíduo a cada filigrana de vida, do poder de performatizar (vigor estético) o viver. E é através da vocoperformance dos cancionistas brasileiros, impregnada dos miasmas da genealogia do país, que o ouvinte daqui pode brincar de viver "um outro" sem tornar-se "o outro", sendo o que se "é".

A canção popular, enquanto espaço de gaia ciência e jogo lúdico, portanto, lugar da criação, permite ao brasileiro a reconstrução contínua de sua mitopoética, o que lhe solapa a dor e libera alegria: vontade de potência, desrecalque. E assim a eficácia do cancionista brasileiro se verifica na competência demonstrada no amalgamar "alta cultura", "folclore" e informação massificada e no modo próprio de disseminar o resultado disso através dos meios de mediação. E fazer do corpo o mediador.

É por isso que, na canção “Ok, Ok, Ok” (2018), a tropical melancolia de Gilberto Gil é composta pelo projeto (utópico) dos parangolés de Hélio Oiticica, pela TV ("ok, ok") entre árvores cortadas, e pela revisão da fala ("ok") vazia de ação. Entre musgos e música, caminha o possível super-homem que Gilberto Gil é. Por sua vez, o elemento vivencial direto propõe a expansão do elemento transgressivo: lugar de fala é lugar de diálogo, real, sem mascaramento, sem silenciamento de nenhum dos interlocutores. É isso que Elza Soares propõe em Deus é Mulher (2018), por exemplo: horizontalidade. No jogo representacional, além do "eu" que fala por "nós", há um "eu" que fala por "si", expondo-se solar, luminoso. 0 matriarcado evocado e cantado por Elza Soares empodera subjetividades e corpos profanados pela tirania patriarcal messiânica. Reforçando a ideia central deste texto, a saber, a canção popular, mesmo sendo de massa, singulariza o ouvinte. Este diagnóstico 
precisa e deve ser problematizado noutra oportunidade, desnaturalizando as razões das contradições das ideias de Brasil e brasilidade, encarando-as como problemas culturais.

\section{Bibliografia}

Adorno, Theodor (1980), "Lírica e Sociedade", in Os Pensadores, São Paulo, Abril, 193-208.

-- / M. Horkheimer (1985), Dialética do Esclarecimento, Rio de Janeiro, Jorge Zahar.

Antunes, Arnaldo (2004), Saiba, Rio de Janeiro, BMG.

Bethânia, Maria (1972), Drama, Rio de Janeiro, Philips Records.

Buarque, Chico (2012), Na Carreira, Rio de Janeiro, Biscoito Fino.

Carlos, Erasmo (2001), Pra Falar de Amor, Rio de Janeiro, Coqueiro Verde.

Eco, Umberto (2001), Apocalípticos e Integrados, São Paulo, Perspectiva.

Gil, Gilberto (2018), Ok Ok Ok Ok, Rio de Janeiro, Geleia Geral.

Homero (2003), Hinos Homéricos, Brasília, UNB.

-- (2000), Odisseia, Rio de Janeiro, Ediouro.

Lévi-Strauss, Claude (1997), Olhar Escutar Ler, São Paulo, Companhia das Letras.

Liv, Sovik (2009), Aqui Ninguém é Branco, Rio de Janeiro, Aeroplano.

Mautner, Jorge (2012), "A Amálgama do Brasil Universal", in Filosofia e Cultura, Rio de Janeiro, Quintal, 106-117.

Mercury, Daniela (2003), Eletrodoméstico, Rio de Janeiro, BMG. 
Nascimento, Abdias (2016), O Genocídio do Negro Brasileiro, São Paulo, Perspectiva.

Oliveira, Luís Inácio (2008), Do Canto e do Silêncio das Sereias, São Paulo, EDUC.

Pessoa, Fernando (1971), Seleção Poética, Rio de Janeiro, Instituto Nacional do Livro.

Puterman, Paulo (1994), Indústria Cultural. A Agonia de um conceito, São Paulo, Perspectiva.

Risério, Antonio (2007), A Utopia Brasileira e os Movimentos Negros, São Paulo, 34.

Santos, Joel Rufino dos (1997), "Culturas Negras, Civilização Brasileira", in Revista do Patrimônio Histórico a Artístico Nacional, no 25, IPHAN/MinC, 4-9.

Soares, Elza (2018), Deus é Mulher, São Paulo, Deckdisc.

Tatit, Luiz (1996), O Cancionista, São Paulo, EdUSP.

Leonardo Davino de Oliveira é professor de Literatura Brasileira na Universidade do Estado do Rio de Janeiro (UERJ). Desenvolve pesquisa sobre poesia e vocoperformance. É autor do blog Lendo Canção. É autor do livro Canção. A Musa híbrida de Caetano Veloso (2012); e coorganizador e autor dos livros Palavra Cantada. Estudos transdisciplinares (2014); Conversas sobre Literatura em Tempos de Crise (2017); Bioescritas/Biopoéticas. Pensamento em trânsito (2018); e Poesia Contemporânea. Crítica e transdisciplinaridade (2018). 